\title{
Systemic anticancer therapy (SACT) for lung cancer and its potential for interactions with other medicines
}

\author{
Ryan Panchal \\ Imperial College London, Exhibition Road, London SW7 2AZ, UK \\ Correspondence to: Ryan Panchal. Email: ryan.panchal12@imperial.ac.uk
}

\begin{abstract}
Background: Systemic anticancer therapy, comprising chemotherapy agents alongside targeted therapies and immunotherapy, is clinically indicated for late-stage lung cancer. It is delivered in regimens often containing multiple anticancer agents as well as supportive care medicines to reduce side effects, raising potential for polypharmacy and therefore the possibility of drug-drug interactions with medicines taken for comorbidities. A pharmacy-led process commonly performed to assist safe prescribing in secondary care is medicines reconciliation; its benefit in minimising interactions involving systemic anticancer therapy medicines has not been assessed previously.

Objectives: The objectives were to characterise the potential drug-drug interactions between systemic anticancer therapy medicines for lung cancer and other medicines and to evaluate the rate of medicines reconciliation being performed and the extent of documentation of potential interactions (clinical audit).

Methodology: This retrospective case series study involved recording the medicines being taken by lung cancer patients undergoing systemic anticancer therapy elicited in consultations at Chelsea and Westminster Hospital, United Kingdom. Potential interactions were identified and characterised in terms of severity using the British National Formulary and other sources. Patient consultation records were also searched for documentation of medicines reconciliation and acknowledgement of potential drug-drug interactions.
\end{abstract}

Results: Twenty-three patients were included in this study. Eighty-eight potential drug-drug interactions were identified across 21 patients, $39 \%$ (34/88) of which involved the supportive care medicine dexamethasone. $3.0 \%$ of consultations included a documented medicines reconciliation, and $15.9 \%$ of potential interactions were documented in the notes, with no correlation between the two. Potentially serious interactions were significantly more likely to be documented $(p<0.05)$.

Conclusions: Many potential drug-drug interactions involving anticancer agents and supportive care medicines exist; particular attention should be paid to dexamethasone. Documentation of interactions and medicines reconciliation occur much less often than expected, suggesting there is scope for implementing methods of safe prescribing to prevent adverse drug effects.

Keywords: systemic anticancer therapy, clinical audit, lung cancer, medicines reconciliation, drug-drug interactions

Published: 04/09/2017

Received: 30/05/2017

ecancer 2017, 11:764 https://doi.org/10.3332/ecancer.2017.764

Copyright: (c) the authors; licensee ecancermedicalscience. This is an Open Access article distributed under the terms of the Creative Commons Attribution License (http://creativecommons.org/licenses/by/3.0), which permits unrestricted use, distribution, and reproduction in any medium, provided the original work is properly cited. 


\section{Introduction}

\section{Systemic anticancer therapy (SACT)}

There are many different treatment options for lung cancer, and these are influenced by type, extent and progression of disease. These treatments can be categorised into surgery, radiotherapy and systemic anticancer therapy (SACT), combinations of which are also possible. While surgery and radiotherapy tend to be of use in local, early-stage disease, SACT is largely used as first-line treatment in advanced stage IIIb-IV non-small-cell lung cancer (NSCLC), with extensive nodal involvement and metastases, to 'improve survival, disease control and quality of life' and is the preferred treatment for both limited and extensive small-cell lung cancer (SCLC) [1]. It is planned in cycles, between which the patient is reviewed for response to therapy.

SACT can be divided into three categories, based on mechanism of action in treating cancer. The most extensive group, chemotherapy, involves the use of cytotoxic drugs to directly destroy tumour cells. It has multiple applications in NSCLC, due to the various intentions of use across most stages of lung cancer. As an adjunct or in combination with radiotherapy, it can be considered pre-operatively in early-disease (stage I-II) patients suitable for surgery; adjuvant chemotherapy aiming to kill cancer cells following radiotherapy is an option in stage II-III disease [2]. There are multiple classes of chemotherapy drug available, with a variety of intracellular targets such as DNA and microtubules. Biological therapies, the second group, are anticancer agents that prevent the spread of cancer by 'interfering with specific molecules involved in tumour growth and progression' [3], as opposed to killing tumour cells directly. These targeted therapies have further developed as a result of advancements in tumour analysis for protein mutations that cause uncontrolled proliferation, such as those in epidermal growth factor receptor (EGFR) and anaplastic lymphoma kinase (ALK) [4]. The third mechanism of SACT is immunotherapy, where monoclonal antibodies recruit the immune system to recognise and attack malignant cells [5]. Table 1 details the SACT agents recommended for use in lung cancer.

Application of SACT involves the use of combination therapies. The most recent statistics of the commonest regimens for lung cancer are shown in Figure 1.

Supportive care medicines are often prescribed as part of the SACT regimen to prevent side effects from occurring. These include various antiemetics such as aprepitant, domperidone, and ondansetron, to combat nausea and vomiting, a common adverse effect of most anticancer agents [6]. Notably, some have higher potential for nausea than others, particularly cisplatin, and different regimens thus require varying doses of antiemetic [17]. Corticosteroids, such as dexamethasone, also counter nausea but additionally reduce the incidence and severity of skin rash, another frequent adverse reaction [6]. Other medicines include folic acid and vitamin B12 for the antifolate drug pemetrexed $[18,19]$ and hydration guidelines for the nephrotoxic platinum-based compounds [20], encompassing combinations of oral furosemide, intravenous saline, and magnesium or potassium salt solutions [21, 22].

\section{Drug-drug interactions}

As discussed, cancer patients for whom SACT is indicated take a multitude of medicines, either within a complex regimen or due to a range of supportive therapies [23]. This increases the likelihood of drug-drug interactions (DDIs), where concurrent administration of two drugs allows one to influence the activity of another [24]. Moreover, interlinking these factors, older patients are the typical demographic of cancer and thus are more likely to be taking multiple regular medicines due to increased comorbidities [25-27].

DDIs, including those involving SACT medicines, can be beneficial and lead to a synergistic (augmented) effect of both drugs, a concept utilised in combination anticancer therapy [28]. However, there is potential for negative outcomes; due to the large number and difference in mechanisms of action between anticancer agents, there are a multitude of adverse DDls involving chemotherapy drugs [28, 29]. Importantly, several SACT agents, including cisplatin, crizotinib, and EGFR tyrosine kinase inhibitors (TKIs), are CYP450 substrates, meaning they can influence hepatic metabolism of many drugs [29, 30]. Other possible DDIs include platinum-based compounds with nephrotoxic agents such as NSAIDs, a synergistic interaction causing impaired renal function [31], and EGFR-TKIs with antacids, which raise stomach $\mathrm{pH}$ and thus prevent absorption of the anticancer agent [32]. 
Table 1. Summary of anticancer agents used in lung cancer with indications, class and mechanism of action. Taken and adapted with kind permission from [6], contributions from [1, 2, 4, 7-15].

\begin{tabular}{|c|c|c|c|}
\hline Anticancer agent & Indication(s) in lung cancer & Class of anticancer agent & Main mechanism \\
\hline Cyclophosphamide & Extensive SCLC & Nitrogen mustard & \multirow{4}{*}{ Intrastrand cross linking of DNA } \\
\hline \multirow{3}{*}{ Carboplatin, cisplatin } & Stage I-II NSCLC (adjuvant) & \multirow{3}{*}{ Platinum-based compound } & \\
\hline & Stage IIIb-IV NSCLC (palliative) & & \\
\hline & All-stage SCLC (palliative) & & \\
\hline Pemetrexed & $\begin{array}{l}\text { Stage IIIb-IV non-squamous NSCLC } \\
\text { (first line) }\end{array}$ & Folate antagonist & \multirow{2}{*}{$\begin{array}{l}\text { Blocking the synthesis of DNA and/ } \\
\text { or RNA }\end{array}$} \\
\hline Gemcitabine & Stage IIIb-IV squamous NSCLC (first-line) & Pyrimidine pathway antimetabolite & \\
\hline Doxorubicin & Extensive SCLC & Anthracycline & $\begin{array}{l}\text { Multiple effects on DNA/RNA syn- } \\
\text { thesis and topoisomerase action }\end{array}$ \\
\hline Docetaxel, paclitaxel & Stage IIIb-IV NSCLC (first line) & Taxane & \multirow{3}{*}{$\begin{array}{l}\text { Microtubule assembly; prevents } \\
\text { spindle formation }\end{array}$} \\
\hline Vincristine & Extensive SCLC & \multirow{2}{*}{ Vinca alkaloid } & \\
\hline Vinorelbine & Stage IIIb-IV squamous NSCLC (first line) & & \\
\hline Topotecan & Relapsed SCLC & Campothecin & \multirow{2}{*}{ Inhibition of topoisomerase } \\
\hline Etoposide & All-stage SCLC (palliative) & Other plant derivative & \\
\hline \multirow{2}{*}{$\begin{array}{l}\text { Afatinib, erlotinib, } \\
\text { gefitinib }\end{array}$} & $\begin{array}{l}\text { Stage IV-NSCLC + EGFR mutation } \\
\text { (first line) }\end{array}$ & \multirow{2}{*}{$\begin{array}{l}\text { Epidermal growth factor receptor } \\
\text { (EGFR)-tyrosine kinase inhibitor (TKI) }\end{array}$} & \multirow{4}{*}{$\begin{array}{l}\text { Inhibition of kinases involved in } \\
\text { growth factor receptor transduction }\end{array}$} \\
\hline & Stage IV NSCLC (second line if refractory) & & \\
\hline Crizotinib & $\begin{array}{l}\text { Stage IIIb-IV NSCLC + ALK translocation } \\
\text { (second line) }\end{array}$ & Anaplastic lymphoma kinase (ALK) inhibitor & \\
\hline Nintedanib & $\begin{array}{l}\text { Stage IIIb-IV non-squamous NSCLC } \\
\text { (second line, if progressive disease after } \\
\text { first line) }\end{array}$ & $\begin{array}{l}\text { Vascular endothelial growth factor receptor } \\
\text { (VEGFR1-3), fibroblast growth factor receptor } \\
\text { (FGFR1-3) and platelet-derived growth factor } \\
\text { receptor (PDGFRa, } \beta \text { ) inhibitor }\end{array}$ & \\
\hline Nivolumab & $\begin{array}{l}\text { Stage IV squamous and non-squamous } \\
\text { NSCLC }\end{array}$ & $\begin{array}{l}\text { Anti-programmed cell death-1 } \\
\text { (PD-1) monoclonal antibody }\end{array}$ & Recruitment of T cells \\
\hline
\end{tabular}

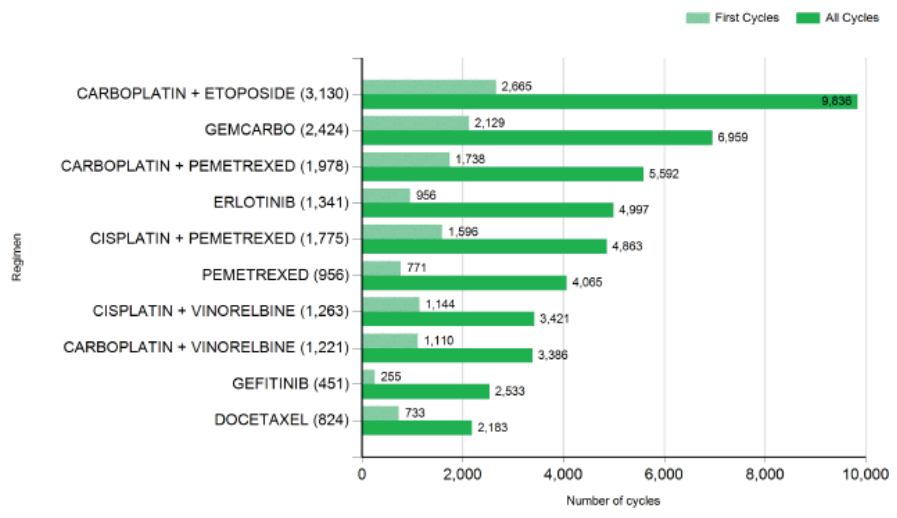

Figure 1. Most common SACT regimens for lung cancer between January and December 2014. Key: GEMCARBO=gemcitabine + carboplatin. Taken from [16]. 
The impact of DDIs directly on healthcare is poorly characterised. However, the broader group of adverse drug reactions (ADRs) place a significant strain on patients and hospitals, accounting for $6.5 \%$ of all hospital admissions, with a total cost per year of over $£ 500,000$ to the NHS [33, 34]. The proportion of this attributed to DDIs is debatable; some suggest an increased risk of readmission related to DDIs [35], particularly in the elderly [36], while other reviews propose the opposite [37,38]. Nevertheless, as the potential for DDIs in SACT patients is high, methods to increase awareness are crucial to minimise risk of adverse events with which they are associated [39, 40].

\section{Medicines reconciliation}

With regard to safe medicine prescribing, it is important that healthcare professionals (HCPs) are conscientious in maintaining the efficacy of medicines, in order for patients to get the best out of their treatment [27, 41]. This concept is known as medicines optimisation and comprises four guiding principles to improve patient outcome, as outlined by the Royal Pharmaceutical Society [42]: aiming to understand the patient's experience; evidence-based choice of medicines; ensuring medicines use is as safe as possible; and making medicines optimisation part of routine practice. A major aspect of medicines optimisation that contributes to these aims is medicines reconciliation (Med-Rec), the process of ensuring the medicines a patient is taking are correctly documented [43].

This involves 'creating and maintaining the most accurate list possible' of the patient's medicines, and then 'comparing... with the current list in use, recognising any discrepancies, and documenting any changes, thereby resulting in a complete list of medicines, accurately communicated' [27, 44], as defined by the Institute of Healthcare Improvement (IHI). These tasks can be summarised into three elements to form 'reliable' reconciliation: verification of the list of current medicines; validation (a review of the current medicines by a trained and competent HCP, noting whether to continue or alter any doses); and clarification, where the current list is compared with the prescribed 'medication order' [41, 44].

Previous studies highlight the potential for problems in healthcare without a formal Med-Rec procedure; unintentional discrepancies were found in $70 \%$ of medicines prescribed on admission (covering $60 \%$ of patients) in a large systematic review by Garfield [41, 45]. Actively implementing the process is also found to be beneficial; it decreases the rate of 'medication errors' by $70 \%$ and ADRs by $15 \%[44,46,47]$ in one hospital setting, while another trial found that it reduced potential ADRs by $80 \%$ [48]. This suggests Med-Rec is an important part of preventing harm to patients.

\section{Rationale for study}

As clarified, there is a considerable risk of DDIs occurring between anticancer agents, plus various supportive care medicines as part of SACT regimens, and other medicines being taken by patients. The complexity of regimens in lung cancer specifically, utilising drugs with various mechanisms, adds to the potential risk of harm. It was therefore of interest to characterise the severity of these potential DDIs (PDDIs), and review whether established processes of Med-Rec, or simply documentation of PDDls, could have a role in preventing harm. Numerous studies report aspects of these separately: DDIs involving general chemotherapy have been identified retrospectively in several studies [49-55]; while outcomes of pharmacy-led intervention with Med-Rec [39, 56-62] have also been analysed. However, combining severity of PDDIs and improvement of patient safety has not been carried out previously.

\section{Aims, objectives and standards}

\section{Aims}

The aim is to evaluate the potential for DDIs between medicines in SACT regimens and other medicines taken by lung cancer patients treated at Chelsea and Westminster Hospital (CWH).

\section{Objectives}

1. To identify and characterise PDDIs present between SACT medicines (comprising anticancer agents and supportive care medicines) and other medicines taken by the patients.

2. To assess the process of Med-Rec and evaluate documentation of PDDIs by prescribing HCPs (clinical audit). 


\section{Standards for clinical audit}

1. $100 \%$ of consultations with a prescribing HCP since the patient started their current SACT regimen include a documented Med-Rec.

2. $100 \%$ of PDDIs between SACT medicines and other medicines had been acknowledged and documented by a prescribing HCP.

\section{Methodology}

\section{Study design, inclusion, and exclusion criteria}

This was a single-centre, retrospective case series study. Patients were selected for inclusion if diagnosed with lung cancer and undergoing a SACT regimen as of 31st March 2016 under the care of the Oncology team (led by Professor Mark Bower and Dr Tom Newsom-Davis) at CWH.

\section{Data collection}

For each patient, every instance of documented patient contact at CWH during their SACT regimen was compiled from the patient records. The chosen start point was the last consultation with a prescribing HCP before starting the current SACT regimen in which a full medicines history was taken. For patients on a maintenance SACT regimen, data were recorded from the last consultation in which a full medicines history was elicited before starting the SACT regimen. The endpoint was the cut-off date of 31st March 2016. Data recorded for each consultation include documentation of medicines being taken and changes to the medicine profile as a result of the consultation.

\section{Identifying PDDIs}

A 'drug chart' overviewing how the medicine profile changed for each patient during their SACT regimen was then created from the data collection spreadsheet (Appendix 1). PDDIs were identified using three primary sources: the British National Formulary (BNF); Summary of Product Characteristics (SPC) at www.medicines.org.uk; and the London Cancer Alliance (LCA) protocols for each SACT regimen. Only PDDIs involving a SACT medicine-either the anticancer agent, or any prescribed supportive care medicine-were noted, and not between any two non-SACT medicines taken concurrently. Component drugs within a preparation were studied individually.

\section{Assessment of Med-Rec and documentation of PDDIs}

The same patient consultation records were analysed for documentation both of Med-Rec being performed and of any DDIs by prescribing HCPs.

\section{Definitions}

'PDDI' (potential drug-drug interaction) is defined as a possible DDI between two medicines (as reported in the BNF, SPC, or LCA protocols) that may have occurred when the patient was taking both concurrently.

'Anticipated DDI' is defined as a possible DDI that was identified but did not occur due to intervention before both medicines were being taken simultaneously. There is therefore no possibility of an adverse event due to this DDI occurring.

A DDI is 'identified' if noted by the author during retrospective analysis of the collected data; 'acknowledged' or 'documented' DDIs are those identified and written down during a consultation by a prescribing HCP.

\section{Results}

Twenty-three patients met the criteria for inclusion in this study. SACT regimens being followed, listed by route of administration, are shown in Table 2 . 
Table 2. SACT regimens of all patients $(n=23)$.

\begin{tabular}{|l|l|}
\hline SACT regimen & Frequency (\%) \\
\hline Intravenous & $14(60.9)$ \\
- Pemetrexed (maintenance) & $-7(30.4)$ \\
$\quad$ - Post-pemetrexed + cisplatin & $-6(26.1)$ \\
- Post-gemcitabine + carboplatin & $-1(4.3)$ \\
- Nivolumab & $-3(13.0)$ \\
- Gemcitabine + carboplatin & $-2(8.7)$ \\
- Etoposide + carboplatin & $-1(4.3)$ \\
- Pemetrexed + carboplatin & $-1(4.3)$ \\
\hline Oral & $7(30.4)$ \\
- Gefitinib & $-4(17.4)$ \\
- Erlotinib & $-2(8.7)$ \\
- Crizotinib & $-1(4.3)$ \\
\hline Combined (intravenous and oral) & $\mathbf{2 ( 8 . 7 )}$ \\
- Carboplatin + vinorelbine & $-1(4.3)$ \\
- Docetaxel + nintedanib & $-1(4.3)$ \\
\hline
\end{tabular}

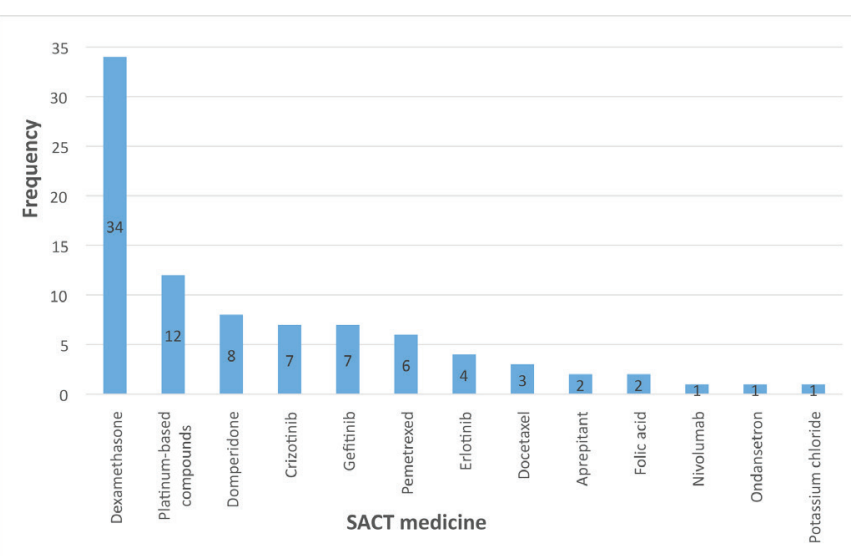

Figure 2. Frequency of PDDIs (total $n=88$ ) for each of the 13 SACT medicines that had at least one identified PDDI.

\section{Identified PDD/s}

A total of 88 instances of PDDIs involving SACT medicines across 21 patients were identified. This total includes anticipated DDIs $(n=13)$. Figure 2 presents the SACT medicines with at least one identified PDDI.

In order to present these data qualitatively, PDDIs were grouped based on effect of interaction and mechanism of the interacting medicine. These 30 distinct DDIs are summarised in Table 3. 
Table 3. Summary of the identified PDDIs ( $n=30$ ). Key: UGT=UDP-glucuronosyltransferase; ACEls=angiotensin-converting enzyme (ACE)

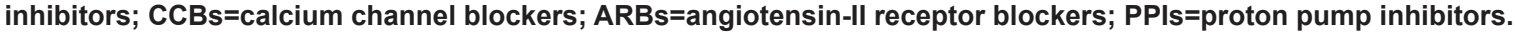

\begin{tabular}{|c|c|c|c|c|}
\hline SACT medicine & Interacting (class of) drug & Possible outcome (effect of interaction) & $\begin{array}{l}\text { Severity of } \\
\text { interaction }\end{array}$ & $\mathbf{n}$ \\
\hline \multirow{2}{*}{ Aprepitant } & Ritonavir & Aprepitant toxicity (increased exposure) & Non-serious & 1 \\
\hline & Warfarin & $\begin{array}{l}\text { Reduced anticoagulation (reduced exposure to } \\
\text { warfarin) }\end{array}$ & Non-serious & 1 \\
\hline \multirow[t]{2}{*}{ Crizotinib } & $\begin{array}{l}\text { UGT substrates (amoxicillin, colecalciferol, } \\
\text { diazepam, levomepromazine, metoclo- } \\
\text { pramide, mirtazapine) }\end{array}$ & Various (increased exposure to UGT substrates) & Unknown & 6 \\
\hline & Dexamethasone & Poor crizotinib efficacy (reduced exposure) & Unknown & 1 \\
\hline \multirow{8}{*}{ Dexamethasone } & $\begin{array}{l}\text { Antihypertensives (ACEls, CCBs, ARBs, } \\
\text { beta-blockers, nitrates) }\end{array}$ & $\begin{array}{l}\text { Raised blood pressure (antagonised effect of } \\
\text { antihypertensives) }\end{array}$ & Non-serious & 11 \\
\hline & $\begin{array}{l}\text { Antidiabetics (metformin, gliclazide, } \\
\text { linagliptin) }\end{array}$ & $\begin{array}{l}\text { Raised blood glucose (antagonised effect of } \\
\text { antidiabetics) }\end{array}$ & Non-serious & 6 \\
\hline & Diuretics (furosemide, bendroflumethiazide) & Hypokalaemia and associated signs and symptoms & Non-serious & 5 \\
\hline & Aspirin & $\begin{array}{l}\text { Gastrointestinal bleeding and ulceration (reduced } \\
\text { exposure to salicylate) }\end{array}$ & Non-serious & 5 \\
\hline & Calcium carbonate & $\begin{array}{l}\text { Hypocalcaemia and associated signs and symptoms } \\
\text { (reduced exposure to calcium salts) }\end{array}$ & Non-serious & 4 \\
\hline & Coumarins & $\begin{array}{l}\text { Enhanced (high-dose corticosteroids) or reduced } \\
\text { anticoagulation (increased or reduced exposure to } \\
\text { coumarins) }\end{array}$ & Potentially serious & 1 \\
\hline & Phenindione & $\begin{array}{l}\text { Enhanced or reduced anticoagulation (increased } \\
\text { or reduced exposure to phenindione) }\end{array}$ & Non-serious & 1 \\
\hline & Ritonavir & $\begin{array}{l}\text { Adrenal suppression (increased exposure to } \\
\text { corticosteroids) }\end{array}$ & Potentially serious & 1 \\
\hline \multirow{2}{*}{ Docetaxel } & CYP3A inhibitors (paracetamol, PPIs) & Docetaxel toxicity (increased exposure) & Unknown & 2 \\
\hline & Clarithromycin & $\begin{array}{l}\text { Myelosuppression; docetaxel toxicity (increased } \\
\text { exposure) }\end{array}$ & Potentially serious & 1 \\
\hline \multirow{3}{*}{ Domperidone } & Opioid analgesics (codeine, morphine) & $\begin{array}{l}\text { Gastroparesis (antagonised gastrointestinal effects } \\
\text { of domperidone) }\end{array}$ & Non-serious & 5 \\
\hline & Clarithromycin & $\begin{array}{l}\text { Domperidone toxicity (increased exposure to } \\
\text { domperidone); ventricular arrhythmias }\end{array}$ & Potentially serious & 2 \\
\hline & Tiotropium & $\begin{array}{l}\text { Gastroparesis (antagonised gastrointestinal effects } \\
\text { of domperidone) }\end{array}$ & Non-serious & 1 \\
\hline \multirow{2}{*}{ Erlotinib } & $\begin{array}{l}\mathrm{PPIs} / \mathrm{H} 2 \text { antagonists/antacids (lansopra- } \\
\text { zole, ranitidine, sodium bicarbonate) }\end{array}$ & Poor efficacy (reduced exposure to erlotinib) & Unknown & 3 \\
\hline & Statins & Myopathy & Unknown & 1 \\
\hline
\end{tabular}


Table 3. Continued.

\begin{tabular}{|c|c|c|c|c|}
\hline Folic acid & Sodium bicarbonate & $\begin{array}{l}\text { Folate deficiency and associated signs and } \\
\text { symptoms (reduced exposure to folic acid) }\end{array}$ & Non-serious & 2 \\
\hline \multirow{4}{*}{ Gefitinib } & CYP3A4 inhibitors (diclofenac, clindamycin) & Gefitinib toxicity (increased exposure) & Unknown & 2 \\
\hline & PPIs (lansoprazole, omeprazole) & Poor gefitinib efficacy (reduced exposure) & Unknown & 2 \\
\hline & CYP3A4 inducers (nevirapine, flucloxacillin) & Poor gefitinib efficacy (reduced exposure) & Unknown & 2 \\
\hline & Warfarin & $\begin{array}{l}\text { Enhanced anticoagulation (increased exposure } \\
\text { to warfarin) }\end{array}$ & Potentially serious & 1 \\
\hline Nivolumab & Dexamethasone & Systemic immunosuppression & Unknown & 1 \\
\hline Ondansetron & Sertraline & Enhanced serotonergic effects & Non-serious & 1 \\
\hline Pemetrexed & $\begin{array}{l}\text { Nephrotoxic drugs (ibuprofen, ACEls, sul- } \\
\text { phamethoxazole) }\end{array}$ & $\begin{array}{l}\text { Nephrotoxicity; pemetrexed toxicity (increased } \\
\text { exposure) }\end{array}$ & Non-serious & 6 \\
\hline \multirow{2}{*}{$\begin{array}{l}\text { Platinum-based } \\
\text { compounds (cispla- } \\
\text { tin, carboplatin) }\end{array}$} & $\begin{array}{l}\text { Nephrotoxic drugs (aspirin, ibuprofen, } \\
\text { ACEIs, sulphamethoxazole) }\end{array}$ & Nephrotoxicity & Unknown & 7 \\
\hline & Diuretics (bendroflumethiazide, furosemide) & Nephrotoxicity; ototoxicity & Non-serious & 5 \\
\hline Potassium chloride & Irbesartan & Hyperkalaemia and associated signs and symptoms & Potentially serious & 1 \\
\hline
\end{tabular}

The most common identified DDI was that of dexamethasone + antihypertensives (12.5\%), followed by: platinum-based compounds + nephrotoxic drugs (8.0\%); crizotinib + UGT substrates, dexamethasone + antidiabetics; pemetrexed + nephrotoxic drugs (each $6.8 \%)$. The remaining PDDIs had five or fewer instances. In terms of severity, there were six 'potentially serious' DDIs, equating to $8.0 \%$ of the total number.

\section{Medicines reconciliation and documentation of PDDIs}

Standard 1: $100 \%$ of consultations with a prescribing HCP since the patient started their current SACT regimen include a documented Med-Rec.

Outcome 1 (standard not met): $3.0 \%$ of consultations with a prescribing HCP since the patient started their current SACT regimen include a documented Med-Rec.

A total of 480 instances of documented patient contact were recorded across all 23 patients. Forty-eight of these were excluded from further analysis: eight were phone calls, three were radiology scan appointments, and 37 were consultations with non-prescribing HCPs.

Of the remaining 432 instances, 13 (3.0\%, across 7 patients) included a documented Med-Rec. Additionally, 95.7\% of patients had at least one full medicines history elicited by a prescribing HCP. This translates to a full medicines history being taken in $11.8 \%$ of consultations.

Standard 2: $100 \%$ of identified PDDIs between SACT medicines and other medicines had been acknowledged and documented by a prescribing HCP. 
Outcome 2 (standard not met): 15.9\% of identified PDDIs between SACT medicines and other medicines had been acknowledged and documented by a prescribing HCP.

Of the 88 instances of PDDIs, 14 (15.9\%, across 8 patients) were acknowledged and documented. These are summarised in Table 4.

Comparison of severity and probability of documentation was performed using Fisher's exact test. Instances of PDDI with an unknown severity ( $n=30$ across both documented and non-documented DDIs) were omitted. Using a standard alpha-level of 0.05 , the null hypothesis can be rejected (d.f. $=1$, two-tailed $\underline{p=0.019}$ ), indicating that potentially serious DDIs were significantly more likely to be documented.

Documented PDDIs were also analysed in relation to Med-Rec processes. None of the 14 PDDIs were acknowledged by a prescribing $\mathrm{HCP}$ in the same consultation as a documented Med-Rec. Two (14.3\%) were elicited after a full medicines history was taken in the same consultation.

Thirteen of the 14 documented PDDIs can be considered anticipated DDIs, where intervention took place before the interaction could occur. The remaining one instance, gefitinib + warfarin, was acknowledged and documented after both medicines were taken concurrently.

\section{Discussion}

\section{Identified PDDIs}

The wide-ranging nature of this study means there are several different aspects suitable for analysis. Firstly, the variety of SACT regimens-10 in total—confirm the multitude of treatment options for late-stage lung cancer patients and compare reasonably well with national statistics [16].

Table 4. Summary of acknowledged and documented instances of PDDIs $(n=14)$.

\begin{tabular}{|c|l|l|l|l|}
\hline \multirow{2}{*}{ Patient \# } & SACT medicine & \multicolumn{1}{|c|}{$\begin{array}{c}\text { Interacting } \\
\text { medicine }\end{array}$} & \multicolumn{1}{|c|}{ Effect of interaction } & $\begin{array}{c}\text { Severity of } \\
\text { interaction }\end{array}$ \\
\hline \multirow{2}{*}{1} & Aprepitant & Ritonavir & Increased exposure to aprepitant & Non-serious \\
\cline { 2 - 5 } & Dexamethasone & Ritonavir & $\begin{array}{l}\text { Increased exposure to corticosteroids, causing } \\
\text { increased risk of adrenal suppression }\end{array}$ & $\begin{array}{l}\text { Potentially } \\
\text { serious }\end{array}$ \\
\hline 2 & Nivolumab & Dexamethasone & Increased risk of systemic immunosuppression & Unknown \\
\hline \multirow{2}{*}{3} & Aprepitant & Warfarin & Reduced anticoagulant effect of warfarin & Non-serious \\
\cline { 2 - 5 } & Dexamethasone & Coumarins & $\begin{array}{l}\text { Enhanced (high-dose corticosteroids) or } \\
\text { reduced anticoagulant effect of coumarins }\end{array}$ & $\begin{array}{l}\text { Potentially } \\
\text { serious }\end{array}$ \\
\cline { 2 - 5 } & Dexamethasone & Phenindione & $\begin{array}{l}\text { Enhanced or reduced anticoagulant effect } \\
\text { of phenindione }\end{array}$ & Non-serious \\
\hline \multirow{2}{*}{4} & Gefitinib & Warfarin & Enhanced anticoagulant effect of warfarin & $\begin{array}{l}\text { Potentially } \\
\text { serious }\end{array}$ \\
\hline 5 & Gefitinib & Lansoprazole & Reduced exposure to gefitinib & Unknown \\
\hline 6 & Gefitinib & Flucloxacillin & Reduced exposure to gefitinib & Unknown \\
\hline \multirow{2}{*}{7} & Erlotinib & Lansoprazole & Reduced exposure to erlotinib & Unknown \\
\cline { 2 - 5 } & Erlotinib & Statin & Increased risk of myopathy & Unknown \\
\hline \multirow{2}{*}{8} & Gefitinib & Nevirapine & Reduced exposure to gefitinib & Unknown \\
\cline { 2 - 5 } & Gefitinib & Omeprazole & Reduced exposure to gefitinib & Unknown \\
\cline { 2 - 5 } & Gefitinib & Diclofenac & Increased exposure to gefitinib & Unknown \\
\hline
\end{tabular}


Regarding the interactions, nearly all patients (91.3\%) had at least one identified PDDI, highlighting the importance of characterising them well. Of particular significance were the PDDIs involving supportive care medicines, which accounted for $55 \%$ of the total. Most previous studies looking at DDIs involving chemotherapy only consider the anticancer agent [50,51,54], although van Leeuwen did report supportive care medicines to be involved in $86 \%$ of all identified PDDIs for the cohort studied [55], further supporting their clinical relevance in DDIs.

The major SACT medicine of note here was dexamethasone, which comprised $39 \%$ of the total number. Moreover, two further PDDIs were identified involving dexamethasone prescribed separately from the SACT regimen. DDIs with corticosteroids have been reported in the literature-van Leeuwen's retrospective study found that dexamethasone was the major supportive care medicine involved [55], and Lam considered it a 'cancer-related drug' with a variety of mechanisms of interaction [49]. Additionally, a quarter of PDDIs involving dexamethasone were classified as potentially serious. This raises the question of its safety, particularly as it was a prescribed component of all intravenous combination SACT regimens for these patients (Appendix 2). However, regimens are carefully designed in terms of dose, timing, and frequency to minimise harm, with low-dose dexamethasone being taken for only three days for every cycle in these LCA-approved regimens. Nevertheless, caution should be exercised considering the wide range of drugs with which it potentially interacts, especially antihypertensives, which was the single-most common PDDI. Indeed, the high frequency reflects the high prevalence of hypertension in the population, particularly the elderly [63] and therefore suggests it is an important comorbidity to consider.

The next most commonly involved SACT medicine were the platinum-based compounds. This meant that cisplatin and carboplatin were the anticancer agents with the most PDDIs, a finding corroborated by Mouzon in a retrospective study [50] and a review by Scripture [29]. All PDDIs for these were linked with nephrotoxicity, which was also the potential outcome in the interactions involving pemetrexed, another nephrotoxic anticancer agent. Indeed, combining the PDDIs for all three makes kidney damage the most common potential outcome (20.4\%). This is particularly dangerous because patients tend to be older and are more likely to have existing renal impairment [64], putting them at greater risk.

Other notable interactions are the remaining potentially serious PDDIs. Although only six of the 30 were classified in this way, each with low frequencies and thus constituting only $8.0 \%$ of the total PDDIs, possible outcomes such as increased risk of bleeding and adrenal suppression mean they should be actively avoided. It is also important to note that 10 PDDIs (totalling 27 instances) did not have a classified severity because they were identified from sources other than the BNF, and so any number could also be potentially serious DDIs, limiting the validity of the results.

\section{Medicines reconciliation and documentation of PDDIs}

The extent of identified interactions, with each patient on average having four PDDIs involving SACT medicines, highlights the necessity of safe prescribing and maintaining patient safety. Clinical audit was an effective method to measure this, identifying results as below expected. For the first standard, a remarkably low value of $3.0 \%$ of consultations including a documented Med-Rec implies there is almost a complete lack of the process occurring. Indeed, this was the case: the 13 documented Med-Recs were only performed when a patient was discharged from $\mathrm{CWH}$, and never in clinic. UK and US guidelines focus primarily on Med-Rec for inpatients, with guidance stating it should be performed for any 'transfer of care', either on admission to hospital, during transfer between wards or on discharge [27]. There is no formally established procedure for patients in ambulatory care at $\mathrm{CWH}$, including this cohort of lung cancer patients attending regular Oncology clinics.

This implies there is scope for implementation of Med-Rec processes for outpatients. IHI suggest collecting a full medicines history and then reviewing if there have been any changes during the consultation, after which a list can be kept 'on file' and verified for each subsequent appointment [65]. Several intervention studies have assessed the advantages of reminders for patients to bring in their regular medicines to clinic followed by correction of the medicines list by patients themselves [66-68], all with encouraging results. A further justification to perform Med-Rec for these patients is that attending clinic could be seen as a 'temporary' transfer of care, during which the processes of Med-Rec should be carried out. 
These shortcomings are also reflected in the second standard regarding PDDI documentation. This again fell well below $100 \%$, suggesting prescribing HCPs do not regularly review the safety of medicines being taken by the patient. Moreover, some were acknowledged simultaneously, meaning the 14 documented PDDls were across eight consultations only. This below-standard practice could be due to the assumption made by HCPs that reviewing medicines comes under the remit of Pharmacy; involving pharmacists in a multidisciplinary team to ensure accurate medicines lists could improve the documentation of PDDIs and thus prevention of interactions, as seen in LopezMartin's single-centre study in Oncology outpatients [61].

While increasing documentation of PDDIs is clearly key, there were some interesting patterns in the acknowledgement of certain categories. The results revealed the potentially serious interactions were significantly more likely to be documented than non-serious PDDIs. There are also three classes of interacting medicine that constitute the majority $(71.4 \%)$ of the documented interactions: anticoagulants, PPIs, and antiretrovirals. This suggests that there may be awareness about certain types of DDI involving specific drugs, without the need for research.

Finally, combining the aspects of the study, it appears that performing Med-Rec does not determine whether PDDIs are documented, which was reasonably assessed by the occurrence of both processes in the same consultation. However, this does not take into account the fact that Med-Rec may not always be carried out in a consultation, even though face-to-face Med-Rec is recommended in local guidelines [41]; it could feasibly be done by comparing to the current medicines list without patient input. This means that there is possible underreporting of Med-Rec, potentially skewing results. Despite this, even just 'verification' correlates poorly (14.3\%) with documentation of PDDIs, suggesting that the majority of acknowledged PDDIs were independent of the taking of a full medicines history in that consultation. Thus, it is beneficial to look at some of the many techniques already established to improve identification of potential interactions, such as the pharmacist-led PINCER [69], the screening tools for elderly patients STOPP/START [70], and My Medicines Passport, a patient-oriented booklet for recording medicines launched in $\mathrm{CWH}$ [71].

\section{Conclusion}

In summary, this study provides a broad review of the common and potentially serious DDIs between SACT medicines and other medicines taken in a cohort of lung cancer patients. It also confirms the lack of established procedure for Med-Rec in these patients and highlights the scope for improvement in identifying more potential interactions, particularly as cancer patients are at risk of polypharmacy. However, the multidisciplinary care required in oncology, including general practice, must be taken into account; thus, implementing these processes in a hospital setting would not eliminate all risk of drug-related harm, but rather, contribute to the bigger picture of ensuring safe medicine prescribing across the whole of the patient journey.

\section{Ethical considerations}

Ethics approval is not required for this work as it is part of a service evaluation and improvement project. An ethics waiver was given by Chelsea and Westminster Hospital NHS Foundation Trust Research and Development lead and NRES for CLAHRC NWL Medicines Optimisation projects. 


\section{Appendices}

Appendix 1. Example of section of 'drug chart' created to identify concurrent administration of SACT medicines with other medicines. Medicines in bold are anti cancer agents and supportive care medicines constituting SACT medicines, with generic name if applicable and route of administration in brackets. Medicines in italics are other medicines being taken by the patient, with generic name if applicable and route of administration if not oral in brackets. The columns are dates of consultations occurring in which medicines being taken were elicited. Key: orange cell = medicine regularly being taken; blue cell = medicine being taken as required.

\begin{tabular}{|c|c|c|c|c|c|c|c|}
\hline Patient \#3 (AB) & $22 / 09 / 2015$ & $23 / 09 / 2015$ & $24 / 09 / 2015$ & $25 / 09 / 2015$ & $26 / 09 / 2015$ & $27 / 09 / 2015$ & $28 / 09 / 2015$ \\
\hline \multicolumn{8}{|l|}{ Dexamethasone (PO) } \\
\hline \multicolumn{8}{|l|}{ Folic acid (PO) } \\
\hline \multicolumn{8}{|l|}{ Aprepitant (PO) } \\
\hline \multicolumn{8}{|l|}{ Ondansetron (IV) } \\
\hline \multicolumn{8}{|l|}{ Pemetrexed (IV) } \\
\hline \multicolumn{8}{|l|}{ Cisplatin (IV) } \\
\hline \multicolumn{8}{|l|}{ Magnesium sulphate (IV) } \\
\hline \multicolumn{8}{|l|}{ Ondansetron (PO) } \\
\hline \multicolumn{8}{|c|}{ Vitamin B12 (hydroxocobalamin, IM) } \\
\hline \multicolumn{8}{|c|}{ Terbinafine } \\
\hline \multicolumn{8}{|l|}{ Nicotine (patch) } \\
\hline \multicolumn{8}{|l|}{ Paracetamol } \\
\hline \multicolumn{8}{|l|}{ Gabapentin } \\
\hline \multicolumn{8}{|c|}{ MST/Zomorph (morphine sulphate) } \\
\hline \multicolumn{8}{|l|}{ Omeprazole } \\
\hline \multicolumn{8}{|l|}{ Diazepam } \\
\hline \multicolumn{8}{|l|}{ Sertraline } \\
\hline \multicolumn{8}{|l|}{ Metoclopramide } \\
\hline \multicolumn{8}{|c|}{ Oramorph (morphine sulphate) } \\
\hline \multicolumn{8}{|c|}{ Truvada (tenofovir + emtricitabine) } \\
\hline \multicolumn{8}{|l|}{ Darunavir } \\
\hline \multicolumn{8}{|l|}{ Ritonavir } \\
\hline \multicolumn{8}{|l|}{ Septrin (co-trimoxazole) } \\
\hline Denosumab (SC) & & & & & & & \\
\hline
\end{tabular}

Appendix 2. All anti cancer agents and supportive care medicines used as part of SACT regimens for treatment of the selected patient sample.

\begin{tabular}{|c|c|c|c|}
\hline SACT regimen & $\begin{array}{l}\text { Route of } \\
\text { regimen }\end{array}$ & Supportive care medicines used & $\begin{array}{l}\text { Route of supportive } \\
\text { care medicine }\end{array}$ \\
\hline \multirow{3}{*}{$\begin{array}{l}\text { Pemetrexed } \\
\text { (maintenance) }\end{array}$} & \multirow{3}{*}{ Intravenous } & Folic acid & Oral \\
\hline & & Ondansetron & Intravenous and oral \\
\hline & & Vitamin B12 (hydroxocobalamin) & Intramuscular \\
\hline \multirow{7}{*}{$\begin{array}{l}\text { Pemetrexed + } \\
\text { cisplatin }\end{array}$} & \multirow{7}{*}{ Intravenous } & Aprepitant & \multirow{4}{*}{ Oral } \\
\hline & & Dexamethasone & \\
\hline & & Domperidone & \\
\hline & & Folic acid & \\
\hline & & Magnesium sulphate & Intravenous \\
\hline & & Ondansetron & Intravenous and oral \\
\hline & & Vitamin B12 (hydroxocobalamin) & Intramuscular \\
\hline
\end{tabular}


Appendix 2. Continued.

\begin{tabular}{|c|c|c|c|}
\hline \multirow{3}{*}{$\begin{array}{l}\text { Gemcitabine + } \\
\text { carboplatin }\end{array}$} & \multirow{3}{*}{ Intravenous } & Domperidone & Oral \\
\hline & & Dexamethasone & \multirow{2}{*}{ Intravenous and ora } \\
\hline & & Ondansetron & \\
\hline Nivolumab & Intravenous & None & N/A \\
\hline \multirow{2}{*}{$\begin{array}{l}\text { Etoposide + } \\
\text { carboplatin }\end{array}$} & \multirow{2}{*}{ Intravenous } & Dexamethasone & \multirow{2}{*}{ Intravenous } \\
\hline & & Ondansetron & \\
\hline \multirow{7}{*}{$\begin{array}{l}\text { Pemetrexed + } \\
\text { carboplatin }\end{array}$} & \multirow{7}{*}{ Intravenous } & Aprepitant & \multirow{4}{*}{ Oral } \\
\hline & & Dexamethasone & \\
\hline & & Domperidone & \\
\hline & & Folic acid & \\
\hline & & Magnesium sulphate & Intravenous \\
\hline & & Ondansetron & Intravenous and oral \\
\hline & & Vitamin B12 (hydroxocobalamin) & Intramuscular \\
\hline Gefitinib & Oral & None & N/A \\
\hline Erlotinib & Oral & None & $\mathrm{N} / \mathrm{A}$ \\
\hline Crizotinib & Oral & None & $\mathrm{N} / \mathrm{A}$ \\
\hline \multirow{5}{*}{$\begin{array}{l}\text { Carboplatin + } \\
\text { vinorelbine }\end{array}$} & \multirow{5}{*}{$\begin{array}{l}\text { Intravenous } \\
\text { and oral }\end{array}$} & Aprepitant & Oral \\
\hline & & Dexamethasone & \multirow{2}{*}{ Intravenous and ora } \\
\hline & & Ondansetron & \\
\hline & & Magnesium sulphate & \multirow{2}{*}{ Intravenous } \\
\hline & & Potassium chloride & \\
\hline \multirow{3}{*}{$\begin{array}{l}\text { Docetaxel + } \\
\text { nintedanib }\end{array}$} & \multirow{3}{*}{$\begin{array}{l}\text { Intravenous } \\
\text { and oral }\end{array}$} & Domperidone & Oral \\
\hline & & Dexamethasone & \multirow{2}{*}{ Intravenous and oral } \\
\hline & & Ondansetron & \\
\hline
\end{tabular}

\section{References}

\section{NICE (2011) Lung cancer: diagnosis and management}

2. BMJ Best Practice Non-small cell lung cancer - treatment - details - best practice - English [Online] Available from: http://bestpractice. bmj.com/best-practice/monograph/1082/treatment/details.html [accessed: 18th March 2016]

3. Healthcare Improvement Scotland (2013) Systemic anti-cancer therapy governance framework and audit tool

4. Kumar P, Clark M (2012) Kumar and Clark's Clinical Medicine. [Online]. 8th ed. Kumar P, Clark M (eds.) Elsevier Available from: http:// store.elsevier.com/Kumar-and-Clarks-Clinical-Medicine/isbn-9780702044991/

5. Pardoll DM (2012) The blockade of immune checkpoints in cancer immunotherapyNat Rev Cancer [Online] Nature Publishing Group, a division of Macmillan Publishers Limited 12(4) 252-264 Available from: doi:10.1038/nrc3239 [accessed: 10th July 2014] https://doi.org/10.1038/nrc3239 PMID: 22437870 PMCID: 4 856023 
6. Rang HP, Ritter JM, and Flower RJ, et al (2016) Rang and Dale's Pharmacology 8th ed Elsevier

7. Cullen M (2003) Lung cancer * 4: Chemotherapy for non-small cell lung cancer: the end of the beginning Thorax 58(4) 352356 Available from: doi:10.1136/thorax.58.4.352 [accessed: 14th May 2016] https://doi.org/10.1136/thorax.58.4.352 PMID: 12668803 PMCID: 1746634

8. Abratt RP, Hart GJ (2006) 10-year update on chemotherapy for non-small cell lung cancerAnn Oncol 17 Suppl 5(suppl_5) v33-36 Available from: doi:10.1093/annonc/mdj947 [accessed: 14th May 2016] https://doi.org/10.1093/annonc/mdj947 PMID: 16807460

9. Rudd GN, Hartley JA, Souhami RL (1995) Persistence of cisplatin-induced DNA interstrand crosslinking in peripheral blood mononuclear cells from elderly and young individualsCancer Chemother Pharmacol 35(4) 323-326 Available from: doi:10.1007l s002800050240 https://doi.org/10.1007/BF00689452 PMID: 7828275

10. Poklar N, Pilch DS, and Lippard SJ, et al (1996) Influence of cisplatin intrastrand crosslinking on the conformation, thermal stability, and energetics of a 20-mer DNA duplexProc Natl Acad Sci 93(15) 7606-7611 https://doi.org/10.1073/pnas.93.15.7606 PMID: $\underline{8755522}$ PMCID: $\underline{38793}$

11. Sahu A, Prabhash K, and Noronha V, et al (2013) Crizotinib: a comprehensive reviewSouth Asian JCancer 2(2) 91-97 https://doi. org/10.4103/2278-330X.110506

12. Shaw AT, Yeap BY, and Mino-Kenudson M, et al (2009) Clinical features and outcome of patients with non-small-cell lung cancer who harbor EML4-ALKJ Clin Oncol 27(26) 4247-4253 https://doi.org/10.1200/JC0.2009.22.6993 PMID: 19667264 PMCID: 2744268

13. Sasaki T, Rodig SJ, and Chirieac LR, et al (2010) The biology and treatment of EML4-ALK non-small cell lung cancer Eur J Cancer 46(10) 1773-1780 https://doi.org/10.1016/j.ejca.2010.04.002 PMID: 20418096 PMCID: 2888755

14. Reck M, Kaiser R, and Mellemgaard A, et al (2014) Docetaxel plus nintedanib versus docetaxel plus placebo in patients with previously treated non-small-cell lung cancer (LUME-Lung 1): a phase 3, double-blind, randomised controlled trial Lancet Oncol 15(2) 143-155 https://doi.org/10.1016/S1470-2045(13)70586-2 PMID: 24411639

15. Sundar R, Cho BC, and Brahmer JR,et al (2015) Nivolumab in NSCLC: latest evidence and clinical potential Ther Adv Med Oncol 7(2) 85-96 https://doi.org/10.1177/1758834014567470 PMID: 25755681 PMCID: $\underline{4346216}$

16. Chemotherapy Intelligence Unit National Cancer Intelligence Network Top Regimens by Diagnostic Group (2016) Available from: http:// www.chemodataset.nhs.uk/home

17. Chambers P, Daniels S (2010) Antiemetic guidelines for adult patients receiving chemotherapy and radiotherapy Available from: http://www.londoncancer.org/media/65597/antiemetic-guidelines-november-2010.pdf

18. Ohe $\mathrm{Y}$, Ichinose $\mathrm{Y}$, and Nakagawa $\mathrm{K}$, et al (2008) Efficacy and safety of two doses of pemetrexed supplemented with folic acid and vitamin B12 in previously treated patients with non-small cell lung cancer Clin Cancer Res 14(13) 4206-4212 https://doi. org/10.1158/1078-0432.CCR-07-5143 PMID: 18594001

19. Yang TY, Chang GC, and Hsu SL, et al (2013) Effect of folic acid and vitamin B12 on pemetrexed antifolate chemotherapy in nutrient lung cancer cells BioMed Res Int 2013 1-10

20. Tiseo $\mathrm{M}$, Martelli $\mathrm{O}$, and Mancuso $\mathrm{A}$, et a/Short hydration regimen and nephrotoxicity of intermediate to high-dose cisplatinbased chemotherapy for outpatient treatment in lung cancer and mesothelioma Tumori 93(2) 138-144. PMID: 17557559

21. Cornelison TL, Reed E (1993) Nephrotoxicity and hydration management for cisplatin, carboplatin, and ormaplatin Gynecol Oncol 50(2) 147-158 https://doi.org/10.1006/gyno.1993.1184 PMID: $\underline{8375728}$

22. Oka T, Kimura T, and Suzumura T, et al (2014) Magnesium supplementation and high volume hydration reduce the renal toxicity caused by cisplatin-based chemotherapy in patients with lung cancer: a toxicity study BMC Pharmacol Toxicol 15(1) 70 https:// doi.org/10.1186/2050-6511-15-70 PMID: 25472655 PMCID: $\underline{4272804}$ 
23. Balis FM (1986) Pharmacokinetic drug interactions of commonly used anticancer drugs Clin Pharmacokinet 11(3) 223-235 https://doi.org/10.2165/00003088-198611030-00004 PMID: 2426030

24. Dumbreck S, Flynn A, and Nairn M, et al (2015) Drug-disease and drug-drug interactions: systematic examination of recommendations in 12 UK national clinical guidelines BMJ 350 h949 https://doi.org/10.1136/bmi.h949 PMID: 25762567 PMCID: 4356453

25. Department of Health (2012) Long Term Conditions Compendium of Information 3rd ed Available from: www.gov.uk

26. Duerden M, Avery T, Payne R (2013) Polypharmacy and medicines optimisation making it safe and sound [Online] Kings Fund Available from: doi:10.1136/bmjopen-2013-002913 https://doi.org/10.1136/bmjopen-2013-002913

27. NICE (2015) Medicines optimisation: the safe and effective use of medicines to enable the best possible outcomes [Online] Available from: guidance.nice.org.uk/NG5

28. McLeod HL (1998) Clinically relevant drug-drug interactions in oncology Br JClin Pharmacol [Online] 45(6) 539-544 https://doi. org/10.1046/j.1365-2125.1998.00719.x PMID: 9663808 PMCID: 1873644

29. Scripture CD, Figg WD (2006) Drug interactions in cancer therapy Nat Rev Cancer 6(7) 546-558 https://doi.org/10.1038/nrc1887 PMID: 16794637

30. Song X, Varker H, and Eichelbaum M, et al (2011) Treatment of lung cancer patients and concomitant use of drugs interacting with cytochrome P450 isoenzymes Lung cancer 74(1) 103-111 https://doi.org/10.1016/j.lungcan.2011.01.016 PMID: 21382644

31. Logothetis CJ, Assikis V, and Sarriera JE (2003) Diagnosis, Treatment, and Prevention of Nephrotoxicity of Cancer Therapeutic Agents Holland-Frei Cancer Medicine [Online] 6th ed. BC Decker Available from: http://www.ncbi.nlm.nih.gov/books/NBK12686/ [Accessed: 16th May 2016]

32. Duong S, Leung M (2011) Should the concomitant use of erlotinib and acid-reducing agents be avoided? The drug interaction between erlotinib and acid-reducing agents J Oncol Pharm Pract 17(4) 448-452 https://doi.org/10.1177/1078155210381794

33. Pirmohamed M, James S, and Meakin S, et al (2004) Adverse drug reactions as cause of admission to hospital: prospective analysis of $18 \mathbf{8 2 0}$ patients BMJ 329(7456) 15-19 https://doi.org/10.1136/bmj.329.7456.15 PMID: 15231615 PMCID: 443443

34. NICE (2015) Costing statement: medicines optimisation: implementing the NICE guideline on medicines optimisation (NG5)

35. Moura CS De, Tavares LS, Acurcio FDA (2012) Hospital readmissions related to drug interactions: a retrospective study in a hospital setting Revista de saúde pública 46(6) 1082-1089 https://doi.org/10.1590/S0034-89102013005000001

36. Juurlink DN, Mamdani M, and Kopp A, et al (2003) Drug-drug interactions among elderly patients hospitalized for drug toxicityJAMA 289 (13) 1652-1658 https://doi.org/10.1001/jama.289.13.1652 PMID: 12672733

37. Jankel CA, Fitterman LK (1993) Epidemiology of drug-drug interactions as a cause of hospital admissions Drug safety 9(1) 51-59 https://doi.org/10.2165/00002018-199309010-00005 PMID: 8347291

38. Egger SS, Drewe J, and Schlienger RG (2003) Potential drug-drug interactions in the medication of medical patients at hospital discharge Eur J ClinPharmacol 58(11) 773-778 https://doi.org/10.1007/s00228-002-0557-z PMID: 12634985

39. Crul M, Yap KD, Terpstra WE (2012) Frequent interactions between chemotherapy and community-dispensed drugs in a continuous screening programme Eur J Hosp Pharm Sci Pract 19(2) 171-171

40. Magro L, Moretti U, Leone R (2012) Epidemiology and characteristics of adverse drug reactions caused by drug-drug interactions Expert Opin Drug Saf 11(1) 83-94 https://doi.org/10.1517/14740338.2012.631910

41. Marvin V (2015) Medicines optimisation definitions and standards for review 
42. Royal Pharmaceutical Society (2013) Medicines optimisation: helping patients to make the most of medicines RPS Good Practice Guidance Available from: https://www.rpharms.com/promoting-pharmacy-pdfs/helping-patients-make-the-most-of-their-medicines.pdf

43. North Carolina Center for Hospital Quality and Patient Safety (2006) Medication Safety Reconciliation: Tool Kit

44. Institute for Healthcare Improvement (2011) How-to Guide: Prevent Adverse Drug Events by Implementing Medication Reconciliation Institute for Healthcare Improvement

45. Garfield S, Barber N, and Walley P, et al (2009) Quality of medication use in primary care--mapping the problem, working to a solution: a systematic review of the literature BMC Med 750 https://doi.org/10.1186/1741-7015-7-50 PMID: 19772551 PMCID: $\underline{2758894}$

46. Whittington J, Cohen H (2004) OSF healthcare's journey in patient safety Qual Manag Health Care 13(1) 53-59 https://doi. org/10.1097/00019514-200401000-00005 PMID: 14976907

47. Institute for Healthcare Improvement Accuracy at Every Step: The Challenge of Medication Reconciliation [Online] Available from: http://www.ihi.org/resources/pages/improvementstories/accuracyateverystep.aspx

48. Michels RD, Meisel SB (2003) Program using pharmacy technicians to obtain medication histories Am JHealth Syst Pharm 60(19) 1982-1986. PMID: 14531244

49. Lam MS, Ignoffo RJ (2003) A guide to clinically relevant drug interactions in oncology J Oncol Pharm Pract 9(2) 45-85 https:// doi.org/10.1191/1078155203jp107oa

50. Mouzon A, Kerger J, and D'Hondt L, et al (2013) Potential interactions with anticancer agents: a cross-sectional study Chemotherapy 59(2) 85-92 https://doi.org/10.1159/000351133 PMID: 23881290

51. Riechelmann RP, Del Giglio A (2009) Drug interactions in oncology: how common are they? Ann Oncol 20(12) 1907-1912 https:// doi.org/10.1093/annonc/mdp369 PMID: 19713244

52. Kannan G, Anitha R, and Rani VN, et al (2011) A study of drug-drug interactions in cancer patients of a south Indian tertiary care teaching hospital J Postgrad Med 57(3) 206-210 https://doi.org/10.4103/0022-3859.85207 PMID: 21941058

53. Bayraktar-Ekincioglu A, Demirkan K, and Keskin B, et al (2014) Potential drug interactions and side effects in an outpatient oncology clinic: a retrospective descriptive study Eur J Hosp Pharm Sci Pract 21(4) 216-221 https://doi.org/10.1136/ejhpharm-2014-000449

54. Segal EM, Flood MR, and Mancini RS, et al (2014) Oral chemotherapy food and drug interactions: a comprehensive review of the literature J Oncol Pract 10(4) e255-e268 https://doi.org/10.1200/JOP.2013.001183 PMID: 24756141

55. van Leeuwen RWF, Brundel DHS, and Neef C, et al (2013) Prevalence of potential drug-drug interactions in cancer patients treated with oral anticancer drugs Br JCancer 108(5) 1071-1078 https://doi.org/10.1038/bjc.2013.48 PMID: 23412102 PMCID: $\underline{3619066}$

56. Weingart SN, Cleary A, and Seger AC, et al (2007) Medication reconciliation in ambulatory oncology Jt Comm J Qual Patient Saf 33(12) 750-757 https://doi.org/10.1016/S1553-7250(07)33090-0

57. Bracey G, Miller G, and Franklin BD, et al (2008) The contribution of a pharmacy admissions service to patient care Clin Med 8(1) 53-57 https://doi.org/10.7861/clinmedicine.8-1-53

58. Gleason KM, McDaniel MR, and Feinglass J, et al (2010) Results of the medications at transitions and clinical handoffs (MATCH) study: an analysis of medication reconciliation errors and risk factors at hospital admission J Gen Int Med 25(5) 441-447 https://doi.org/10.1007/s11606-010-1256-6 
59. Nightingale G, Hajjar E, and Swartz K, et al (2015) Evaluation of a pharmacist-led medication assessment used to identify prevalence of and associations with polypharmacy and potentially inappropriate medication use among ambulatory senior adults with cancer J Clin Oncol 33(13) 1453-1459 https://doi.org/10.1200/JCO.2014.58.7550 PMID: 25800766

60. Mekonnen AB, McLachlan AJ, Brien JE (2016) Effectiveness of pharmacist-led medication reconciliation programmes on clinical outcomes at hospital transitions: a systematic review and meta-analysis BMJ Open 6(2) e010003 https://doi.org/10.1136/ bmjopen-2015-010003 PMID: 26908524 PMCID: 4769405

61. Lopez-Martin C, Siles MG, and Alcaide-Garcia J, et al (2014) Role of clinical pharmacists to prevent drug interactions in cancer outpatients: a single-centre experience Int J Clin Pharm 36(6) 1251-1259 https://doi.org/10.1007/s11096-014-0029-4 PMID: $\underline{25326824}$

62. Ho CC, Yang CC, Chou YC (2014) Potential drug-drug interactions in oncology patients receiving anti-cancer drugs in a Tertiary Medical Centre in Taiwan. Pharmacoepidemiol Drug Saf 23(S1) 279-280

63. Vokonas PS, Kannel WB, Cupples LA (1988) Epidemiology and risk of hypertension in the elderly: the Framingham Study J Hypertens 6(1) S3-S9

64. Kafetz K (1983) Renal impairment in the elderly: a review J R Soc Med 76(5) 398-401 PMID: 6191032 PMCID: 1439187

65. Institute for Healthcare Improvement Reconcile Medications in Outpatient Settings [Online] Available from: http://www.ihi.org/resources/ Pages/Changes/ReconcileMedicationsinOutpatientSettings.aspx

66. Varkey P, Cunningham J, Bisping S (2007) Improving medication reconciliation in the outpatient setting Jt Comm J Qual Patient Saf 33(5) 286-292 https://doi.org/10.1016/S1553-7250(07)33033-X PMID: 17503684

67. Nassaralla CL, Naessens JM, and Chaudhry R, et al (2007) Implementation of a medication reconciliation process in an ambulatory internal medicine clinicQual Saf Health Care 16(2) 90-94 https://doi.org/10.1136/qshc.2006.021113 PMID: 17403752 PMCID: $\underline{2653166}$

68. Leonhardt KK, Pagel P, and Bonin D, et al (2008) Creating an Accurate Medication List in the Outpatient Setting Through a PatientCentered Approach In Henriksen K, Battles J, Keyes M (eds.) Advances in Patient Safety: New Directions and Alternative Approaches (Vol. 3: Performance and Tools) (Rockville, MD: Agency for Healthcare Research and Quality (US)) p. 1-15

69. Avery AJ, Rodgers S, and Cantrill JA, et al (2012) A pharmacist-led information technology intervention for medication errors (PINCER): a multicentre, cluster randomised, controlled trial and cost-effectiveness analysis Lancet 379(9823) 1310-1319 https://doi.org/10.1016/S0140-6736(11)61817-5 PMID: 22357106 PMCID: 3328846

70. Gallagher P, Ryan C, and Byrne S, et al (2008) STOPP (Screening Tool of Older Person's Prescriptions) and START (Screening Tool to Alert doctors to Right Treatment)Consensus validation Int J Clin Pharmacol Ther 46(2) 72-83 https://doi.org/10.5414/ CPP46072 PMID: 18218287

71. Barber S, Thakkar K, and Marvin V, et al (2014) Evaluation of my medication passport: a patient-completed aide-memoire designed by patients, for patients, to help towards medicines optimisation BMJ open 4(8) e005608 Available from: doi:10.1136/ bmjopen-2014-005608 [Accessed: 13th March 2016] https://doi.org/10.1136/bmjopen-2014-005608 PMID: 25138809 PMCID: $\underline{4139624}$ 